\title{
Oxymatrine on Hsp90a expression and apoptosis in a model of lung ischemia-reperfusion injury
}

\author{
BING ZHU ${ }^{1 *}$, JIANRU YANG $^{2 *}$, SIFENG CHEN $^{1}$, PEI ZHANG ${ }^{1}$, LIN SHEN $^{1}$, XIAOLONG LI ${ }^{1}$ and JING LI $^{1}$ \\ ${ }^{1}$ Department of Cardiothoracic Surgery, The Second Affiliated Hospital of Chongqing Medical University, \\ Chongqing 400010; ${ }^{2}$ Central Laboratory of Handan Infectious Diseases Hospital, Handan, Hebei 056002, P.R. China
}

Received August 22, 2016; Accepted December 30, 2016

DOI: 10.3892/etm.2017.4098

\begin{abstract}
The protective effects of oxymatrine (OMT) on apoptosis and heat shock protein 90a (Hsp90a) expression in a rabbit model of lung ischemia-reperfusion injury (LIRI) were investigated. The model of LIRI was established in rabbits and they were randomly divided into two groups: The control group (group $\mathrm{C}, \mathrm{n}=10$ ), and experimental group (further divided into groups $\mathrm{E} 1, \mathrm{n}=10$; and group $\mathrm{E} 2, \mathrm{n}=10$ ), to measure the levels of malondialdehyde (MDA) and superoxide dismutase (SOD) activity in lung tissue homogenates at several time points $\left(\mathrm{T}_{0}\right.$, 0 min; $\mathrm{T}_{1}, 60 \mathrm{~min} ; \mathrm{T}_{2}, 120 \mathrm{~min} ; \mathrm{T}_{3}, 180 \mathrm{~min}$; and $\mathrm{T}_{4}, 240 \mathrm{~min}$ ), and to measures changes in lung tissue wet/dry weight ratio (W/D), apoptosis index (AI), and Hsp90a expression and organization at $\mathrm{T}_{2}, \mathrm{~T}_{3}$ and $\mathrm{T}_{4}$. Comparing group $\mathrm{C}$ with groups E1 and E2, the levels of SOD activity and MDA were not significantly different at $\mathrm{T}_{0}$ and $\mathrm{T}_{1}(\mathrm{P}>0.05)$; W/D ratio and AI were significantly higher than in groups $\mathrm{E} 1$ and $\mathrm{E} 2(\mathrm{P}<0.05$, $\mathrm{P}<0.01) ; 120 \mathrm{~min}$ after LIR, MDA, W/D ratio, and AI were lower than in groups E1 and E2 $(\mathrm{P}<0.05, \mathrm{P}<0.01)$. MDA, W/D ratio and $\mathrm{AI}$ were lower in $\mathrm{E} 2$ than in $\mathrm{E} 1(\mathrm{P}<0.05)$, and SOD and Hsp90a expression increased $(\mathrm{P}<0.05)$. The ultrastructure in group $\mathrm{E}$ showed less injury compared with group $\mathrm{C}$. In conclusion, by scavenging oxygen free radicals, OMT can inhibit apoptosis, increase Hsp90a expression, and reduce the injury caused by lung ischemia reperfusion.
\end{abstract}

\section{Introduction}

Ischemia-reperfusion injury (IRI) is a disease caused by ischemia, reperfusion or revascularization to dredge by vascular tissues and organs regain blood, in certain circumstances, the

Correspondence to: Dr Bing Zhu, Department of Cardiothoracic Surgery, The Second Affiliated Hospital of Chongqing Medical University, 74 Linjiang Road, Chongqing 400010, P.R. China

E-mail:drzhb@sina.com

*Contributed equally

Key words: lung ischemia-reperfusion injury, oxymatrine, apoptosis, Hsp90a reperfusion will result in more serious damage to tissues and cells (1-3). The mechanism of ischemia reperfusion injury is very complex, and so far has not been elucidated, but is related to inflammation, endothelial cell injury, energy depletion and production disorder, no reflow phenomenon, calcium overload and oxygen free radical damage.

Lung IRI (LIRI) is one of the main causes of death caused by pulmonary dysfunction in the early postoperative period for patients who underwent double-sleeve lobectomy, lung transplantation, or cardiopulmonary bypass (4-6). At present, there are many methods to the prevention and treatment of LIRI reported in the literature, such as reduction of LIRI by inhibiting neutrophil aggregation and activation. The study found that polyethylene glycol was added to the lungs in a low potassium perfusion solution (7). It can change the interaction between cell and cell, cell and protein as well as with water, to reduce pulmonary edema and play a role of lung protection. In the ischemia period, a large number of free radicals are released in tissues, sulfur based compound free radical causes membrane lipid peroxidation and severe cell damage, and the most serious injury is in pulmonary vascular endothelial cells (8). It has been reported that the addition of $\mathrm{N}$-acetyl cysteine in the perfusion solution can alleviate lung reperfusion injury (9). It is also reported that the occurrence of reperfusion injury can be reduced by reducing the infiltration of inflammatory cells (10). In the process of lung transplantation, the white blood cell filter is used in the heart lung bypass loop to prevent the white blood cells from entering the human pulmonary blood vessel. This experimental method has also achieved some results (11).

Although in recent years, the LIRI has been widely studied, the exact mechanism remains to be elucidated, various measures of prevention and treatment effects are not ideal, and the prevention of LIRI has still not improved. Clinical study found that in lung transplantation due to LIRI pulmonary dysfunction rate was very high, and the treatment was difficult and expensive, many patients needed extra corporeal membrane oxygenator with high mortality rate (12). Pulmonary IRI has become one of the main factors that hinder the development of lung transplantation. Therefore, it is still the focus of the current research to identify the mechanism of LIRI and to search for effective methods and drugs for the prevention and treatment of ischemia reperfusion injury. It is necessary to screen out a more accurate and appropriate lung 
protection method to prevent and reduce the occurrence of IRI in lung transplantation.

Recently, many scholars have focused on the research of IRI protection in traditional Chinese medicine. Danshensu, ligustrazine and oxymatrine (OMT) have been demonstrated significant against inflammation, antioxidant, scavenging oxygen free radicals, to reduce reperfusion injury of tissue (13). OMT is a kind of compound of basic structure of matridine-1-ketone, mainly alkaloids extracted from sophora root or in sophora alopecuroides, and studies show that OMT has a strong pharmacological effect of anti-inflammatory and immunomodulatory, antioxidant and protecting heart and liver ischemia reperfusion (14). However, there is less research on the LIRI of the lungs. We observed the effect of OMT on lung histopathology, levels of malondialdehyde (MDA) and superoxide dismutase (SOD), as well as expression levels of heat shock protein 90a (Hsp90a), to investigate the protective mechanism against LIRI.

\section{Materials and methods}

Experimental animals. A total of 30 healthy, Japanese flap-eared white rabbits, either male or female, weighing 1.8-2.5 kg were used. Rabbits were provided by the Animal Laboratory of Chongqing Academy of Chinese Materia Medica [Chongqing, China; animal certificate no. SCXR(Yu)20070006]. Animals were randomly divided into the control group (group $\mathrm{C}, \mathrm{n}=10$ ) and the experimental group (group $\mathrm{E}, \mathrm{n}=20$ ) which was then further divided according to method of intervention: Cervical vein administration group (group E1, $\mathrm{n}_{1}=10$ ) and left pulmonary administration group (group E2, $\mathrm{n}_{2}=10$ ), and they separately received OMT $(100 \mathrm{mg} / \mathrm{kg}$ ) via pump infusion (OMT batch number: National Medicine Permission no. H20041843; Baoding Sanjiu Jishi Biological Pharmaceutical Co., Ltd., Baoding, China) from the distal heart side, 10 min before hilar blocking and moment of pulmonary blocking.

The model of LIRI was established according to the method by Yamashita et al (15). Heparin $(1.0 \mathrm{mg} / \mathrm{kg})$ was injected via the jugular vein. At $60 \mathrm{~min}$ after ischemia, continuous perfusion was performed and lasted for $180 \mathrm{~min}$. This study was approved by the Animal Ethics Committee of Chongqing Medical University Animal Center.

Biochemical analyses of lung tissue. Lung tissues were collected at the time of chest opening $\left[0 \min \left(\mathrm{T}_{0}\right)\right]$, after ischemia [60 $\mathrm{min}\left(\mathrm{T}_{1}\right)$ ], and following reperfusion [180 $\mathrm{min}$ $\left.\left(\mathrm{T}_{3}\right)\right]$ and [240 $\left.\mathrm{min}\left(\mathrm{T}_{4}\right)\right]$. Lung tissue specimens were used to prepare $10 \%$ homogenates, and samples were preserved at $-20^{\circ} \mathrm{C}$ until further use. The aldehyde shrinkage method was used to determine tissue protein content, and after determining SOD and MDA by the xanthine oxidase method, protein content was determined with a protein quantification kit (Nanjing Jiancheng Bioengineering Institute, Nanjing, China) according to the instructions.

Measurement of lung tissue wet/ dry weight ratio. At $\mathrm{T}_{2}$, $\mathrm{T}_{3}$ and $\mathrm{T}_{4}$, we removed roughly $2 \mathrm{~g}$ of left lung tissue as the wet weight, and the weight after $10 \mathrm{~h}$ of baking in an electric tachometer indicator thermostatic drying oven, was taken as the dry weight. The ratio of the weights was determined as wet/dry (W/D).

Observation of lung tissue morphology. At $\mathrm{T}_{2}, \mathrm{~T}_{3}$ and $\mathrm{T}_{4}$, roughly $1 \times 1 \times 1 \mathrm{~cm}$ pieces of tissue from the lower lobe of left lungs were removed and fixed in $10 \%$ formaldehyde, and conventional processing and sectioning of tissue were performed. Tissue sections underwent H\&E staining, immunohistochemical staining, and observation by light microscopy. Additionally, pieces of lung $(0.1 \times 0.1 \times 0.1 \mathrm{~cm})$ from the lower left lobe (three for each group) were fixed with $2.5 \%$ osmic acid and post fixed with $1 \%$ osmic acid. Tissue was sectioned and treated with glutaraldehyde for electron microscopic observation.

Immunohistochemistry. The non-apoptotic cell detection kit was from Roche Diagnostics (Basel, Switzerland). Hsp90a detection reagent was from Fuzhou Maixin Biotech. Co., Ltd. (Fuzhou, China), and were both used according to the manufacturer's instructions. Apoptosis-positive cell nuclei appeared brown-yellow, and the cytoplasmic expression of Hsp90a expression was brown-yellow. For each tissue section, five random visual fields were observed by light microscopy (20x10 times). We enumerated the apoptosis index (AI) as positive cell number/total cell number x $100 \%$. The same was done for the Hsp90a expression index.

Statistical analysis. Data were analyzed with SPSS 15.0 software (SPSS, Inc., Chicago, IL, USA). Data are expressed as mean \pm standard deviation. One way ANOVA, LSD and t-test were used for comparisons. $\mathrm{P}<0.05$ was considered to indicate a statistically significant difference.

\section{Results}

Measurement of SOD activity and MDA levels. At $\mathrm{T}_{1}$ and $\mathrm{T}_{3}$, SOD and MDA levels in the three groups (group C, E1 and E2) were not significantly different. After $\mathrm{T}_{2}$ and during the LIR period, in group $\mathrm{C}$ the MDA levels progressively increased, while SOD activity remained the same, and compared with groups E1 and E2, the corresponding values were significantly different $(\mathrm{E} 1, \mathrm{P}<0.05$; $\mathrm{E} 2, \mathrm{P}<0.01)$. MDA levels in $\mathrm{E} 1$ were increased over E2, whereas SOD activity was lower compared with E2. The differences were all statistically significant $(\mathrm{P}<0.05$; Table I).

Measurement of W/D ratio, AI and Hsp90a. W/D ratio and $\mathrm{AI}$ of group $\mathrm{C}$ was higher than in groups $\mathrm{E} 1$ or $\mathrm{E} 2$, and the differences were all statistically significant $(\mathrm{P}<0.05, \mathrm{P}<0.01)$. Hsp90a expression was higher in groups E1 and E2 compared with group $\mathrm{C}$, and the differences were statistically significant $(\mathrm{P}<0.05, \mathrm{P}<0.01)$. The $\mathrm{W} / \mathrm{D}$ ratio and AI of group $\mathrm{E} 2$ were significantly lower than in $\mathrm{E} 1(\mathrm{P}<0.05, \mathrm{P}<0.01)$. Hsp90a expression in group E2 was significantly higher than in E1 ( $\mathrm{P}<0.05$; Figs. 1-3).

Lung tissue structural changes by light microscopy. In group $\mathrm{C}$, there was noticeable lung atelectasis, pulmonary interstitial edema, inflammatory cell infiltration, and alveolar exudate (Fig. 4A). In group E, lung injury was significantly reduced, with less inflammatory cell infiltration and complete alveoli (Fig. 4B). 
Table I. Comparison of lung tissue homogenate SOD (U/mg prot) and MDA (nmol/mg prot).

\begin{tabular}{lcccccc}
\hline Index & Group & $\mathrm{T}_{0}$ & $\mathrm{~T}_{1}$ & $\mathrm{~T}_{2}$ & $\mathrm{~T}_{3}$ & $\mathrm{~T}_{4}$ \\
\hline SOD & $\mathrm{C}$ & $14.32 \pm 1.27$ & $15.38 \pm 2.24$ & $13.88 \pm 1.61$ & $13.62 \pm 1.82$ & $12.50 \pm 1.31$ \\
& $\mathrm{E} 1$ & $14.04 \pm 1.42$ & $15.42 \pm 5.00$ & $18.00 \pm 1.81^{\mathrm{a}}$ & $19.26 \pm 6.57^{\mathrm{a}}$ & $22.28 \pm 3.11^{\mathrm{b}}$ \\
& $\mathrm{E} 2$ & $14.12 \pm 1.14$ & $17.10 \pm 4.31$ & $19.94 \pm 6.06^{\mathrm{b}}$ & $21.10 \pm 5.42^{\mathrm{b}}$ & $24.38 \pm 3.61^{\mathrm{b}}$ \\
MDA & $\mathrm{C}$ & $1.06 \pm 0.19$ & $1.21 \pm 0.41$ & $1.50 \pm 0.30$ & $1.54 \pm 0.31$ & $1.76 \pm 0.42$ \\
& E1 & $1.05 \pm 0.23$ & $1.21 \pm 0.19$ & $1.38 \pm 0.31^{\mathrm{a}}$ & $1.05 \pm 0.33^{\mathrm{a}}$ & $1.17 \pm 0.19^{\mathrm{c}}$ \\
& E2 & $1.08 \pm 0.21$ & $1.19 \pm 0.16$ & $1.31 \pm 0.21^{\mathrm{b}}$ & $1.02 \pm 0.31^{\mathrm{b}}$ & $1.12 \pm 0.15^{\mathrm{b}}$ \\
\hline
\end{tabular}

Intra-group comparison with $\mathrm{T}_{0},{ }^{\mathrm{c}} \mathrm{P}<0.01$; comparison with $\mathrm{T}_{1}, \mathrm{~T}_{2}, \mathrm{~T}_{3},{ }^{\mathrm{b}} \mathrm{P}<0.05$; inter-group comparison with group $\mathrm{C},{ }^{\mathrm{a}} \mathrm{P}<0.05$, ${ }^{\mathrm{c}} \mathrm{P}<0.01$; comparison between $\mathrm{E} 2$ and $\mathrm{E} 1,{ }^{\mathrm{b}} \mathrm{P}<0.05$. SOD, superoxide dismutase; MDA, malondialdehyde.

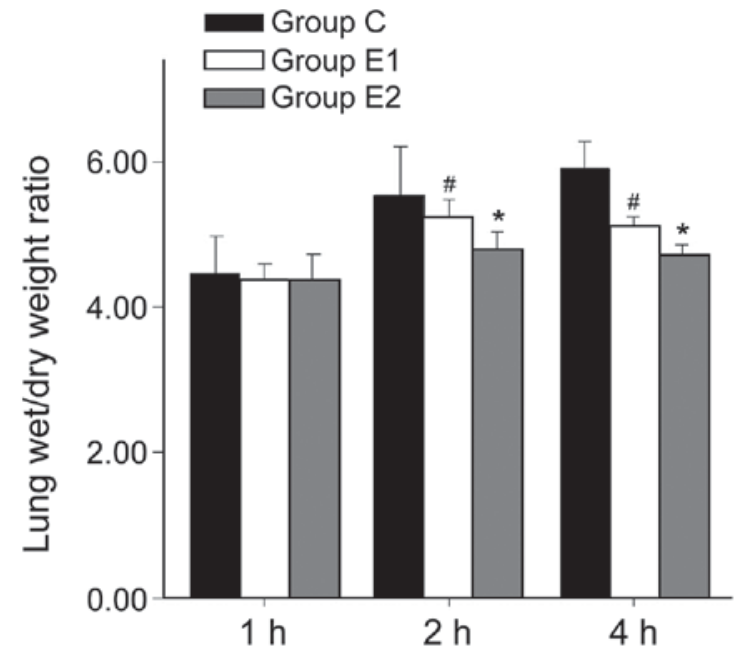

Figure 1. Lung wet/dry weight ratio in 3 different groups. ${ }^{\text {"Comparing with }}$ group $\mathrm{C}, \mathrm{P}<0.05$; ${ }^{*}$ Comparing with group $\mathrm{E} 1, \mathrm{P}<0.05$.

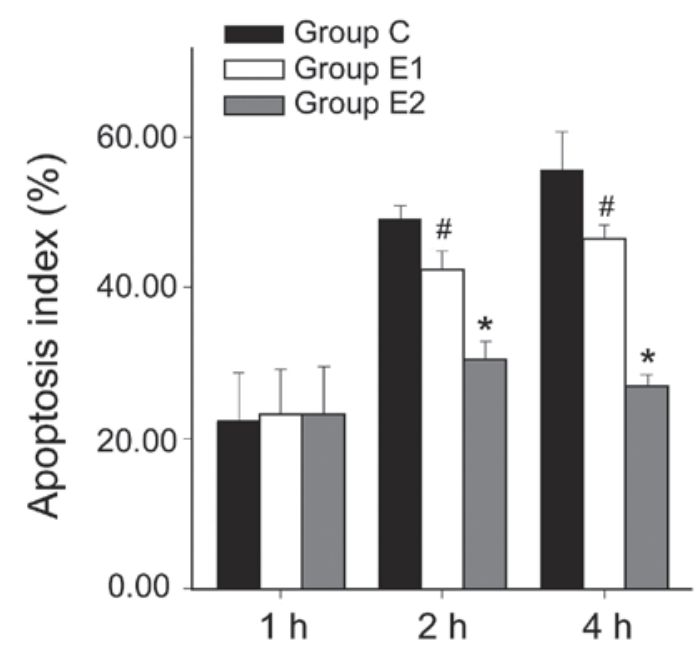

Figure 2. Apoptosis index in 3 different groups. ${ }^{\#}$ Comparing with group $C$, $\mathrm{P}<0.05$; ${ }^{*}$ Comparing with group $\mathrm{E} 1, \mathrm{P}<0.05$.

Lung tissue examination by electron microscopy. In group C, endocytic vesicles inside endothelial cells of small pulmonary arteries increased, and mitochondria appeared swollen and vacuolized. The underlying basement membrane of

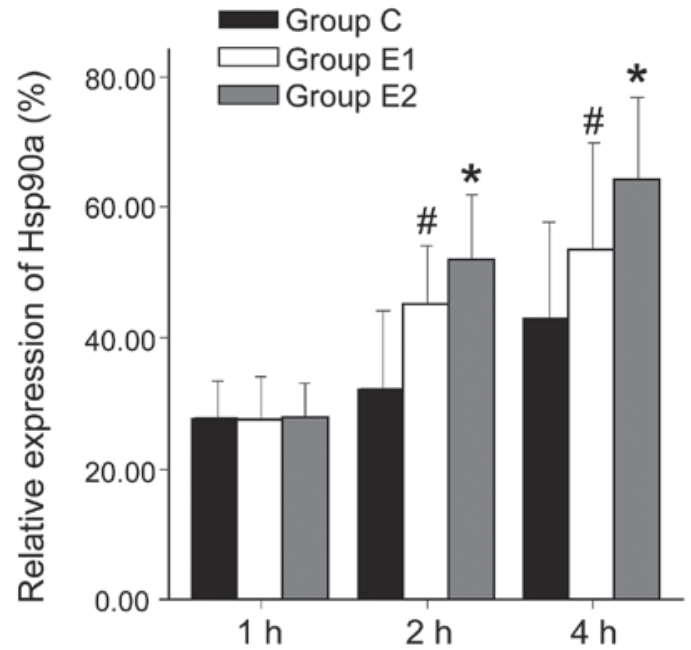

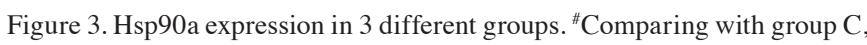
$\mathrm{P}<0.05$; ${ }^{*}$ Comparing with group E1, $\mathrm{P}<0.05$.

endometrial cells appeared with edema and vacuolar degeneration. There were capillary transluminal polymorphonuclear blocks, type II epithelial cell mitochondria were swollen, and apoptotic bodies were visible (Fig. 5A). In group E, endothelial morphology of small pulmonary arteries was mostly normal, the external basement membrane of endothelial cells was complete, and the morphology of type II epithelial cells was not significantly abnormal (Fig. 5B).

\section{Discussion}

The present study is based on the rabbit LIRI experimental model. Histomorphology after LIRI, and observations of tissue biochemistry have shown that LIRI causes increased permeability of the alveolar-capillary barrier, pulmonary interstitial edema, slurry exudation in alveoli, and neutrophil infiltration. Neutrophil accumulation in lung tissue leads to the phenomenon of 'respiratory burst', during which several toxic factors are released including oxygen free radicals, and cause tissue injury $(15,16)$. During reperfusion, oxygen-rich blood provides reactive oxygen species and inflammatory mediators. This produces oxygen free radicals and other reactive oxygen species. Furthermore, neutrophils interact with ischemic endothelial cells, which causes apoptosis and lung injury (15). 

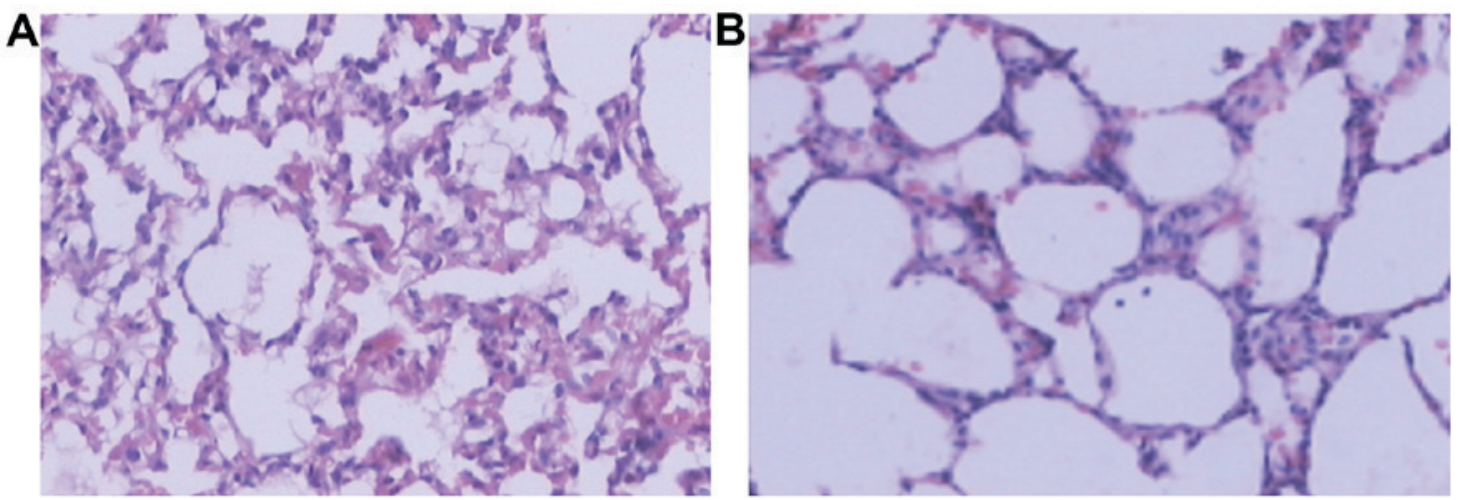

Figure 4. Light microscopy of lung tissue in groups C and E2 at 4 h. (A) Group C, alveolar atelectasis; inflammatory cells exdution in alveolus; (B) group E2, alveolar mild interstitial congestion and alveolar internal hemorrhage.
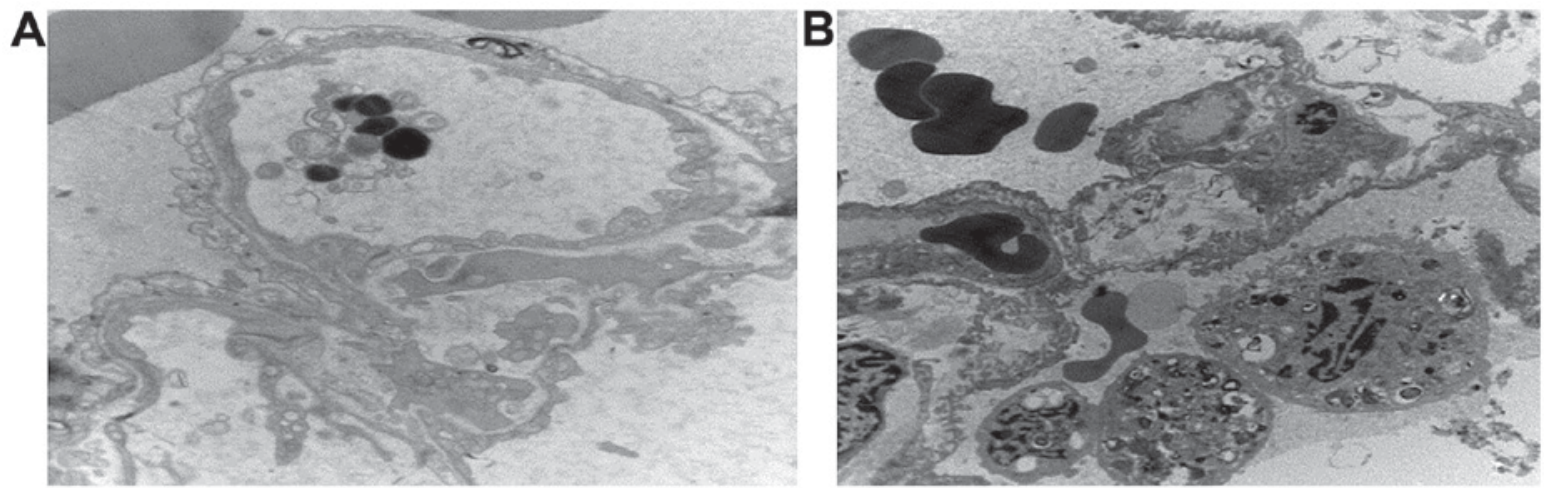

Figure 5. Electron microscopy of lung tissue in groups C and E2 at $4 \mathrm{~h}$. (A) Type 2 alveolar epithelial cell edema; formation of apoptotic body; (B) structure of type 2 alveolar epithelial cell was normal and interstitial edema.

OMT is one of many alkaloids extracted from the sophora root or bitter beans. Modern research has shown that OMT has potent anti-inflammatory, immune regulatory, and antioxidant functions and can protect the heart and liver from IRI $(17,18)$. $\mathrm{Xu}$ et al (19) reported that OMT may inhibit protein kinase activity and the proinflammatory effect of TNF- $\alpha$ by blocking phosphorylation, and thus protect against acute lung injury. Tian et al (20) reported that OMT can effectively clear oxhydryl. OMT reacts with free radicals, forming OMT radicals, which break the chain reaction of lipid peroxidation, and improve the ability of cells to resist oxidation-mediated injury. The present study shows that during lung ischemia and hypoxia, MDA values in groups E1 and E2 are not significantly different with group $\mathrm{C}$. At $2 \mathrm{~h}$ after reperfusion, MDA levels of the control group were significantly higher than in the experimental group, and SOD activity was significantly lower. The data show that oxygen free radicals increase and endogenous antioxidant enzymes are inhibited. After intervention with OMT, the concentration of MDA decreased compared with the group that received no intervention, and SOD activity increased significantly, which suggests that OMT can indirectly inhibit xanthine oxidase, and decrease the production of superoxide anion, or make xanthine oxidase combine with superoxide anion, forming toxic metabolites. OMT can also lower the levels of oxygen free radicals, thus protecting lung tissue from injury caused by oxygen free radicals, and reduce LIRI.
Hsp90a is a member of the heat-shock protein family, which is activated by external stimuli. Under stress, such as in high fever, ischemia, hypoxia, and trauma, it will also increase. Hsp90a acts as both a functional protease and hormone receptor, and can adjust the activity and involvement of transcription of heat shock protein genes, to reduce inflammation, promote anti-oxidation, and inhibit apoptosis (21-23). DeMeester et al (24) used Hsp90a to induce IкB- $\alpha$ expression and observed the function of inhibiting endothelial cell apoptosis (25). The present study shows that Hsp90a was expressed in all groups. However, $2 \mathrm{~h}$ after LIRI in group E, expression levels increased significantly and W/D ratio and AI index decreased. In group E2, Hsp90a was significantly higher than in groups $\mathrm{E} 1$ and $\mathrm{C}$, and W/D ratio and $\mathrm{AI}$ index were significantly lower than in groups E1 and C. Abnormal morphological changes to lung tissue were reduced significantly, suggesting that OMT can increase Hsp90a expression. At the early stage of ischemia and hypoxia, Hsp90a is involved in endogenous protection from injury, inhibiting cell apoptosis and reducing LIRI.

In conclusion, OMT can protect rabbit lung tissue from experimental IRI, through the combined effects of clearing oxygen free radicals, exerting its anti-inflammatory and immune regulatory effects, increasing Hsp90a expression, and inhibiting apoptosis. The results also suggest that the protective effect of OMT is better in the partial pulmonary perfusion group (group E2) than in the systemic administration group 
(group E1), which provides new possibilities for the protection of lung ischemia reperfusion injury.

\section{Acknowledgements}

This study was supported by the National Natural Sciences Foundation of China (grant no. 30471984), the Foundation of Bureau of Public Health of Chongqing (grants nos. 2006-2-001, 2006-B-26 and 2010-2-127) and the project Innovation of Science and Technology, Chongqing Science and Technology Commission (project no. cstc2013jcyjA10108).

\section{References}

1. Cuzzocrea S, Riley DP, Caputi AP and Salvemini D: Antioxidant therapy: A new pharmacological approach in shock, inflammation, and ischemia/reperfusion injury. Pharmacol Rev 53: $135-159,2001$

2. Kin H, Zhao ZQ, Sun HY, Wang NP, Corvera JS, Halkos ME, Kerendi F, Guyton RA and Vinten-Johansen J: Postconditioning attenuates myocardial ischemia-reperfusion injury by inhibiting events in the early minutes of reperfusion. Cardiovasc Res 62: 74-85, 2004.

3. Mori K, Lee HT, Rapoport D, Drexler IR, Foster K, Yang J, Schmidt-Ott KM, Chen X, Li JY, Weiss S, et al: Endocytic delivery of lipocalin-siderophore-iron complex rescues the kidney from ischemia-reperfusion injury. J Clin Invest 115: 610-621, 2005.

4. den Hengst WA, Gielis JF, Lin JY, Van Schil PE, De Windt LJ and Moens AL: Lung ischemia-reperfusion injury: A molecular and clinical view on a complex pathophysiological process. Am J Physiol Heart Circ Physiol 299: H1283-H1299, 2010.

5. Shimamoto A, Pohlman TH, Shomura S, Tarukawa T, Takao M and Shimpo H: Toll-like receptor 4 mediates lung ischemia-reperfusion injury. Ann Thorac Surg 82: 2017-2023, 2006.

6. Ng CS, Wan S, Arifi AA and Yim AP: Inflammatory response to pulmonary ischemia-reperfusion injury. Surg Today 36: 205-214, 2006

7. Jayle C, Hauet T, Menet E, Hébrard W, Hameury F, Eugene M, Carretier $\mathrm{M}$ and Corbi P: Beneficial effects of polyethylene glycol combined with low-potassium solution against lung ischemia/reperfusion injury in an isolated, perfused, functional pig lung. Transplant Proc 34: 834-835, 2002.

8. Hatachi G, Tsuchiya T, Miyazaki T, Matsumoto K, Yamasaki N, Okita N, Nanashima A, Higami Y and Nagayasu T: The poly(adenosine diphosphate-ribose) polymerase inhibitor PJ34 reduces pulmonary ischemia-reperfusion injury in rats. Transplantation 98: 618-624, 2014.

9. Weinbroum AA, Rudick V, Ben-Abraham R and Karchevski E: $\mathrm{N}$-acetyl-L-cysteine for preventing lung reperfusion injury after liver ischemia-reperfusion: A possible dual protective mechanism in a dose-response study. Transplantation 69: 853-859, 2000.

10. Nakano H, Nagasaki H, Barama A, Boudjema K, Jaeck D, Kumada K, Tatsuno M, Baek Y, Kitamura N, Suzuki T, et al: The effects of $\mathrm{N}$-acetylcysteine and anti-intercellular adhesion molecule-1 monoclonal antibody against ischemia-reperfusion injury of the rat steatotic liver produced by a choline-methionine-deficient diet. Hepatology 26: 670-678, 1997.
11. Halldorsson A, Kronon M, Allen BS, Bolling KS, Wang T, Rahman $S$ and Feinberg H: Controlled reperfusion after lung ischemia: implications for improved function after lung transplantation. J Thorac Cardiovasc Surg 115: 415-424; discussion 424-425, 1998.

12. Ali HS, Hassan IF and George S: Extra corporeal membrane oxygenation to facilitate lung protective ventilation and prevent ventilator-induced lung injury in severe Pneumocystis pneumonia with pneumomediastinum: A case report and short literature review. BMC Pulm Med 16: 52, 2016.

13. Zhang H, Wan Z, Yan X, Wang DG, Leng Y, Liu Y, Zhang Y, Zhang $\mathrm{H}$ and Han X: Protective effect of Shenfu injection preconditioning on lung ischemia-reperfusion injury. Exp Ther Med 12: 1663-1670, 2016.

14. Zheng P, Niu FL, Liu WZ, Shi Y and Lu LG: Anti-inflammatory mechanism of oxymatrine in dextran sulfate sodium-induced colitis of rats. World J Gastroenterol 11: 4912-4915, 2005.

15. Yamashita H, Akamine S, Sumida Y, Inoue M, Sawada T, Nagayasu T and Oka T: Inhaled nitric oxide attenuates apoptosis in ischemia-reperfusion injury of the rabbit lung. Ann Thorac Surg 78: 292-297, 2004.

16. Haddad JJ, Olver RE and Land SC: Antioxidant/pro-oxidant equilibrium regulates HIF-1alpha and NF-kappa B redox sensitivity. Evidence for inhibition by glutathione oxidation in alveolar epithelial cells. J Biol Chem 275: 21130-21139, 2000.

17. Zhu XH, Qiu YD, Shi MK and Ding YT: Effects of matrine on cold ischemia and reperfusion injury during orthotopic liver transplantation in rats. World Chin J Digestology 14: 1675-1680, 2006

18. Shang L, Wang L, Sun H and Yang B: Protective effects of oxymatrine on acute myocardial ischemia in rats. J Harbin Med Univ 39: 124-126,129, 2005.

19. Xu GL, Yao L, Rao SY, Gong ZN, Zhang SQ and Yu SQ: Attenuation of acute lung injury in mice by oxymatrine is associated with inhibition of phosphorylated p38 mitogen-activated protein kinase. J Ethnopharmacol 98: 177-183, 2005.

20. Tian X, Cong J and Sun C: SER Study on oxidation sophora clear radical radical and protective effect of thymidylate padiation. J Prev Med Chin People's Liberation Army 14: 412-415, 1996 (In Chinese). http://www.cnki.com.cn/Article/ CJFDTotal-JYYX606.006.htm.

21. Lammi MJ, Elo MA, Sironen RK, Karjalainen HM, Kaarniranta K and Helminen HJ: Hydrostatic pressure-induced changes in cellular protein synthesis. Biorheology 41: 309-313, 2004.

22. Kamal A, Boehm MF and Burrows FJ: Therapeutic and diagnostic implications of Hsp90 activation. Trends Mol Med 10: 283-290, 2004

23. Blagosklonny MV: Hsp-90-associated oncoproteins: Multiple targets of geldanamycin and its analogs. Leukemia 16: 455-462, 2002.

24. DeMeester SL, Buchman TG, Qiu Y, Jacob AK, Dunnigan K, Hotchkiss RS, Karl I and Cobb JP: Heat shock induces IkappaB-alpha and prevents stress-induced endothelial cell apoptosis. Arch Surg 132: 1283-1287; discussion 1287-1288, 1997.

25. Wang YY, Peng YZ and Zhao XH: The research of heat shock protein 90 's expression in hypoxic rat myocardial cells. Program Mod Biomed 7: 486-488, 2007 (In Chinese). http://www.cnki. com.cn/Article/CJFDTotal-SWCX200704003.htm. 